\title{
Merit, approbation and the evolution of social structure
}

Citation for published version (APA):

Cowan, R., \& Jonard, N. (2005). Merit, approbation and the evolution of social structure. UNU-MERIT, Maastricht Economic and Social Research and Training Centre on Innovation and Technology. MERITInfonomics Research Memorandum Series No. 026 https://doi.org/10.26481/umamer.2005026

Document status and date:

Published: 01/01/2005

DOI:

10.26481/umamer.2005026

Document Version:

Publisher's PDF, also known as Version of record

\section{Please check the document version of this publication:}

- A submitted manuscript is the version of the article upon submission and before peer-review. There can be important differences between the submitted version and the official published version of record.

People interested in the research are advised to contact the author for the final version of the publication, or visit the DOI to the publisher's website.

- The final author version and the galley proof are versions of the publication after peer review.

- The final published version features the final layout of the paper including the volume, issue and page numbers.

Link to publication

\footnotetext{
General rights rights.

- You may freely distribute the URL identifying the publication in the public portal. please follow below link for the End User Agreement:

www.umlib.nl/taverne-license

Take down policy

If you believe that this document breaches copyright please contact us at:

repository@maastrichtuniversity.nl

providing details and we will investigate your claim.
}

Copyright and moral rights for the publications made accessible in the public portal are retained by the authors and/or other copyright owners and it is a condition of accessing publications that users recognise and abide by the legal requirements associated with these

- Users may download and print one copy of any publication from the public portal for the purpose of private study or research.

- You may not further distribute the material or use it for any profit-making activity or commercial gain

If the publication is distributed under the terms of Article $25 \mathrm{fa}$ of the Dutch Copyright Act, indicated by the "Taverne" license above, 


\section{MERIT-Infonomics Research Memorandum series}

Merit, Approbation and the Evolution of Social Structure

Robin Cowan \& Nicolas Jonard

2005-026

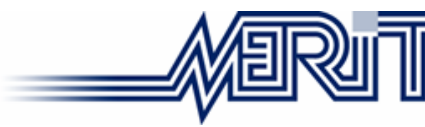

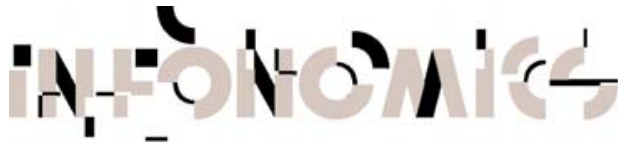

MERIT - Maastricht Economic Research

International Institute of Infonomics

Institute on Innovation and Technology

PO Box 616

6200 MD Maastricht

The Netherlands

T: +31433883875

F: +31433884905

PO Box 616

6200 MD Maastricht

The Netherlands

T: +31 433883875

F: +31 453884905

http://www.merit.unimaas.nl

http://www.infonomics.nl

e-mail:secr-merit@merit.unimaas.nl

e-mail: secr@infonomics.nl 


\title{
Merit, Approbation and the Evolution of Social Structure*
}

\author{
R. COWAN $^{\dagger}$, N. JONARD ${ }^{\ddagger}$ \\ ${ }^{\dagger}$ MERIT, University of Maastricht, P.O. Box 616 \\ 6200 MD Maastricht, The Netherlands \\ ${ }^{\ddagger}$ CNRS, CREA Ecole Polytechnique, 1 Rue Descartes \\ 75005 Paris, France
}

August 12, 2005

\begin{abstract}
In this paper we study a society in which individuals gain utility from income and from social approbation. Income is correlated with class. Approbation is given to an unobservable trait, which must be signalled through the agent's social mobility, i.e. class change. Mobility is driven by a simple mechanism involving inheritance, effort and ability. Thus social structure (class composition) is affected by individuals' quest for approbation, and we study how that affects the emergence and multiplicity of long run social organizations, including hybrid forms of dynasties and meritocracies. Specifically we observe that even though social mobility is driven purely by a meritocratic mechanism, pure dynasties can emerge. We then introduce a feedback between the size of the upper class and its income value, so that effort levels and social structure are jointly endogenous. We derive results on equilibrium effort levels and stationary (when they exist) social structures. Social organization can converge to a unique steady state, multiple long run equilibria or cycles.
\end{abstract}

\section{Introduction}

Most people get value from the approbation of others. The idea that our peers believe we are "special" in some (positive) way tends to increase our utility levels. At the same time there is a fairly natural tendency to grant this approbation when someone does seem special. Different societies, and one society at different points in time, have different ideas

${ }^{*}$ We gratefully acknowledge comments from Avinash Dixit, Steve Durlauf, Alan Kirman, Barkley Rosser, and other participants of the workshop "Networks, Aggregation and Markets" held in Marseilles, June 20 and 21, 2005. Bas Ter Weel and Fred Deroian also provided useful comments on an earlier draft. Corresponding author: r.cowan@merit.unimaas.nl 
about what counts as special in this regard. In a caste society, or an old aristocracy, blood is the key. Approbation is granted to those born into a high caste, and contempt to those born in a low caste. In a pure meritocracy by contrast, approbation is granted to those with merit: those who have skills and/or put in high effort. ${ }^{1}$ Most modern societies are some mix of both ideas, with the general thought that approbation based on merit is somehow more modern. In any society, though, approbation does not come in infinite supplies. The approbation mechanism ensures that if some people get more, others get less. A limited supply is necessary to give approbation any value.

Some sources of approbation are readily visible: skill at basketball or movie acting, for example, or the social status of one's forebears. Others, such as intelligence, are not. The former can simply be displayed; the latter must be signalled by some other means. One means of signalling high skills of various kinds is to enter a social or income class that differs from one's origin class, for example through a particular profession. Social approbation follows. This is what this paper is about. We focus on attempts to acquire public approbation through class mobility. Individuals try to signal their talent through the application of effort, which can result in a class change and the acquisition (or loss) of status. This has long run consequences on social structure, and can also alter the values attached to the classes themselves.

The observation that individuals compete for approbation from their peers is not new (on the competition for approbation, status and other scarce social resources see Hirsch, 1976). In the literature on conspicuous consumption for instance, public approbation is granted for the ownership of large wealth which, because it is not directly observable, is signalled by heavy consumption of some positional good. ${ }^{2}$ In that literature what matters is relative rather than absolute position. In Frank (1985a), Fershtman et al. (1996), or Funk (1996) relative standing in some hierarchical structure enters the utility function directly. In Frank (1985a) an individual's utility increases with his position in the distribution of consumption levels of the positional good. In Fershtman et al. (1996) an individual cares about the average level of human capital in his occupation relative to that in the alternative occupation. Alternatively, rankings can emerge from individuals' desire to perform well in some non-market tournament (such as access to social circles, clubs, marriage, and so on) as in Cole et al. (1992) and Corneo and Jeanne (1998, 1999). There social recognition obtains from marrying the right (high quality) mate or getting one's offspring to marry the right mate, the probability of which is determined by relative performance in the social contest. The desire for status is instrumental, arising endogenously from agents' attempts to manipulate a different argument of the utility function. Ireland (1998) introduces "others" into preferences in a slightly different way: an agent's utility is a convex combination of his or her own fundamental utility, and spectators' estimate of that utility.

Much of this literature concludes that in general the competition for status positions is self-stultifying: if all agents make equivalent attempts to move up the hierarchy (buying cars that are twice as big as their current ones), the result is simply an increase in the resources spent in signalling, and no relative movement of agents within the hierarchy. Thus even

\footnotetext{
1 "Meritocracy" was coined by Young (1958), and defined as a society in which recruitment to social positions is based solely on merit, defined as the combination of ability and effort.

${ }^{2}$ On conspicuous consumption see Marshall (1890), Smith (1776) and Veblen (1899). On status and economic decisions, see the survey by Weiss and Fershtman (1998).
} 
if this behaviour generates growth in output, it generally does not raise aggregate welfare and tends to constitute a social waste. ${ }^{3}$ In his model Funk (1996) argues that although agents continually renew their status goods and so create continued demand and economic accumulation, welfare does not increase, whereas Corneo and Jeanne (1998) find statusseeking beneficial when it happens early in the life cycle. ${ }^{4}$

In the present paper we extend in several directions a framework initially provided in Piketty (1998). ${ }^{5}$ Moving to, or staying in a high income class contributes to utility in two ways: directly, through the utility of income; and instrumentally, in its contribution to public approbation. Mobility is observed, and on that basis public beliefs about who deserves approbation are updated, and the updating mechanism creates a social competition for approbation. Individual effort-provision decisions thus have collective implications regarding the forms of social organization that can emerge. Depending on the importance of the approbation motive and the prevalence of talent, a variety of organizations can emerge, including hybrid forms of dynasties and meritocracies. In addition, we include a feedback between approbation-seeking behaviour and the value from being in a particular class.

The central mechanism in the model is as follows. Social approbation is given to an unobservable trait which must be signalled through the agent's social mobility, and this gives agents an incentive to try to enter or to stay in the high income class. Mobility here is driven by a very simple mechanism involving inheritance, effort and ability, and the mechanism we employ mimics well the structures discussed in the empirical literature on social mobility. ${ }^{6}$ In turn, upward mobility reduces the "market value" of the high class, as entry drives down the income of members. While not reducing the value of the approbation attached to the class, it does reduce the net inducement to attempt to enter, and so changes the amount of entry to it. In general, this provides a regulating effect on mobility and class structure. Class structure and effort thereby become jointly endogenous, and the type of society that emerges, whether of self-made men, nouveaux riches arrivistes, or an Ancien Régime aristocracy is driven by processes internal to the structure of social promotion and demotion. Though the mechanism is simple, cycles, dynasties or meritocracy are all possible outcomes, depending on the values of a few key parameters.

It is worth observing that in our model mobility is driven purely by meritocratic concerns: if an agent has ability and works, he or she will rise (or stay in the top). Thus in terms of motivation (incentives) agents live in a meritocratic system. Social promotion will take place if an agent applies effort to skill, and demotion will happen if effort and skill are lacking. An interesting result then is that under identifiable conditions a purely dy-

\footnotetext{
${ }^{3} \mathrm{~A}$ tax can provide a response to this over-consumption problem; see Ireland (1998).

${ }^{4}$ It is also possible to find a link between income distribution and the status-seeking activities, whereby differences in taste for status among rich and poor induce different investment decisions (in things such as schooling) which can in turn further affect income distribution and growth. See Weiss and Fershtman (1998, section 3.4) on these issues.

${ }^{5}$ The concern in that paper revolves around the possibility that in two otherwise similar societies there can be one in which agents actively seek status whereas in the other status-seeking behaviour is absent. Besides multiplicity, Piketty also discusses the amplifying effect of the status quest on initial inequalities.

${ }^{6}$ On the relative importance of class inheritance, ability and effort for social mobility in the UK, see Breen and Goldthorpe (1999) and Saunders (1997). On how these forces affect social mobility more generally, see for example, Treiman and Ganzeboom (1990), Breen and Goldthorpe (2001), Deardon et al. (1997), Savage and Egerton (1997), Erikson and Goldthorpe (2002).
} 
nastic structure can emerge, in which all agents remain in the social class of their parents. This suggests that defining or identifying a meritocracy is not simply a matter of observing inter-generational (non)mobility (cf. the debate between Saunders, 1997 and Breen and Goldthorpe, 1999). A society in which all promotion is done purely on meritocratic principles can still have a frozen social structure with no inter-generational mobility at all.

The paper is organized as follows: in the next section we present the basic model of agents maximizing utility through choice of effort level. Effort, combined with randomly assigned ability levels, determines whether the agent stays in his inherited origin class, or moves to a different destination class. In section 3 we derive results on effort levels for different types of agents, and on the long run social class structure. In section 4 we introduce social competition explicitly, by endogenizing incomes within a social class as a function of the size of the class, deriving results on equilibrium effort levels, class structure and efficiency. Section 5 concludes.

\section{The model}

Society consists of two locations $\{0,1\}$, the lower and upper classes respectively, which are populated with a continuum $S$ of individuals having total measure normalized to unity. Each individual $i \in S$ lives for one period during which he has a chance to move between the two classes. Social mobility is influenced by three factors: the origin of $i, \ell_{i} \in\{0,1\}$, the ability of $i$, which can be high or low, $a_{i} \in\{a, A\}$, and the level of effort provided by $i$, which can be high or low, $e_{i} \in\{e, E\}$.

Individuals' origins are inherited without error from their parents. Abilities are identically and independently distributed: independently from the abilities of other agents, and independently of the social class of the agent. ${ }^{7}$ Specifically $i$ 's ability $a_{i}$ is high with probability $p \in(0,1)$, which is known to everyone. Thus there is inter-generational inertia in social class, but none in ability. Finally effort can be thought of as educational investment or harder work in the professional sphere and is, alone, under the control of the agent. Depending on these three factors an individual can stay in his or her origin class, be promoted to the higher class or be demoted to the lower class.

Agents know their origin classes and know their own abilities. On the basis of expected utility they choose effort levels, and then "move" from $\ell_{i}$ to $z_{i}$ (possibly with $z_{i}$ equal to $\left.\ell_{i}\right)$. After all agents have moved, each collects the monetary payoff $r\left(z_{i}\right)$ associated with his or her destination class and public approbation. Individuals die after having given birth to a single offspring who is a member of his or her parent's destination social class. The process then simply iterates.

We look for steady states in effort levels and class sizes, and how their properties are affected by parameters governing mobility.

\section{$2.1 \quad$ Utility}

Utility is driven by income and by public opinion about ability. The former is determined by an agent's destination class; the latter is inferred by the public, from observable information

\footnotetext{
${ }^{7}$ In Section 3.3 that assumption is discussed in greater detail.
} 
about social mobility. Following Piketty (1998), we write utility as

$$
u_{i}=r\left(z_{i}\right)+\lambda \operatorname{Pr}\{A \mid \cdot\}-c\left(e_{i}\right)
$$

with $\lambda$ the importance of approbation (the status motive), $c\left(e_{i}\right)$ the cost of producing effort $e_{i}$ with the normalization that $c(E)=c$ and $c(e)=0$, and $r\left(z_{i}\right)$ the income again normalized so that $r(0)=0$ and $r(1)=1$. Thus we examine a society in which the income level in the upper class is fixed, exceeding that in the lower class, regardless of how densely populated the upper class is. ${ }^{8}$ Finally $\operatorname{Pr}\{A \mid \cdot\}$ is the posterior probability placed by society on $i$ being of high ability conditional on the publicly observable information. The extent to which society grants positive approbation is exactly equal to the probability that society thinks the agent is of high ability, scaled by $\lambda$. The posterior is determined by Bayes' rule: a success, i.e. upwards mobility for low origin people or maintaining the status quo for high origin people, will strengthen the public belief about one's ability; a failure weakens the public belief.

\subsection{Mobility}

We have assumed there are three traits - ability, origin, effort - and each exerts a positive influence on the probability that an agent ends up in the upper class. Social mobility is thus encapsulated in the details of the transition rates $\operatorname{Pr}\left\{z_{i}=z \mid a_{i}, \ell_{i}, e_{i}\right\}$, for which it is natural that high origin, high ability and high effort each independently raises the probability that an agent moves into, or stays in, the upper class. We adopt a (stochastic) majority rule for social mobility. An agent moves to (or stays in) the class corresponding to the majority of his three attributes: origin, ability and effort. Thus the possibility of class change only arises for high-effort, high-ability lower class (who can move up) and low-effort, low-ability rich (who can fall). ${ }^{9}$ Mobility is not deterministic, though: a high-effort, high-ability poor agent rises with probability $u$, while a low-effort, low-ability rich agent falls with probability $d$, as summarized in Table 1 .

Small values of $u$ and $d$ describe a system in which social mobility is low (inertia is high). Depending on the relative magnitudes of $u$ and $d$ the direction of mobility is affected, yielding easier upward than downward mobility $(u>d)$ or vice versa $(u<d)$. Thus $u$ and $d$ can be seen as capturing the degree of inertia in social structure, the importance of luck in social mobility, or both. Setting $u=d=1$ yields a pure deterministic majority rule in which possession of at least two high traits implies membership in high society, and minimum inertia.

One observation here is that for agents of upper class origin, ability and effort are strategic substitutes (having one attribute implies that the other is not needed), whereas for agents of lower class origin they are strategic complements (the absence of one attribute

\footnotetext{
${ }^{8}$ This assumption is relaxed in Section 4 where we introduce a feedback between class size and income.

${ }^{9}$ Savage and Egerton (1997) show that high ability high status children are likely to be high status adults, whereas low ability, low status children are likely to be be low status adults. The probability of ending in the service (upper) class is equal for low ability/high status children and high ability/low status children (about 30 percent). Breen and Goldthorpe (1999) show that different origin classes have different probabilities of ending in a particular destination class. The difference falls when we correct for merit, but it remains that children from lower classes need to show considerably more merit to enter a particular (higher) class than do higher class children. See also Boudon (1974).
} 


\begin{tabular}{cccc}
\hline $\begin{array}{c}\text { Ability } \\
a_{i}\end{array}$ & $\begin{array}{c}\text { Origin } \\
\ell_{i}\end{array}$ & $\begin{array}{c}\text { Effort } \\
e_{i}\end{array}$ & $\begin{array}{c}\text { Social mobility } \\
\operatorname{Pr}\left\{z_{i}=1 \mid a_{i}, \ell_{i}, e_{i}\right\}\end{array}$ \\
\hline$A$ & 1 & $E$ & 1 \\
& & & 1 \\
$A$ & 1 & $e$ & 1 \\
$a$ & 1 & $E$ & $u$ \\
$A$ & 0 & $E$ & $1-d$ \\
$a$ & 1 & $e$ & 0 \\
$A$ & 0 & $e$ & 0 \\
$a$ & 0 & $E$ & 0 \\
& & &
\end{tabular}

Table 1: The probabilistic mechanism driving social mobility.

implies that there is no value in acquiring the other). This difference arises because of the inertia in mobility arising from class origin.

\section{Status, dynasties and meritocracy}

Inferences about ability and thus optimal behaviour are affected by what is public and what is private knowledge. We will focus on the case in which an individual knows both his ability and his effort, but neither is publicly observable. By contrast social mobility, which serves as a signal of ability, is publicly observable. We begin this section with equilibrium behaviour determination and then turn to the evolution of social structure. We finally discuss alternative information regimes and the assumptions of the model.

\subsection{Equilibrium effort levels}

As effort is not observable, we must define public beliefs about individuals' effort levels. As agents know their own abilities, there are four types of agents: upper and lower class origin, crossed with high and low ability levels. Society's beliefs about effort are therefore characterized by a 4-tuple: $q=\left(q_{0, A}, q_{0, a}, q_{1, A}, q_{1, a}\right)$, where $q_{i, j}$ is the probability that an individual of origin $i$ and ability $j$ puts in high effort. With beliefs characterised this way, we define society's posterior as $\operatorname{Pr}\left\{A \mid \ell_{i}, z_{i} ; q\right\}$. Application of Bayes' Rule gives that posterior beliefs about low origin agents are

$$
\begin{aligned}
& \operatorname{Pr}\{A \mid 0,1 ; q\}=\left\{\begin{array}{c}
0, q_{0, A}=0, \\
1, q_{0, A}>0,
\end{array}\right. \\
& \operatorname{Pr}\{A \mid 0,0 ; q\}=\frac{p-p u q_{0, A}}{1-p u q_{0, A}} .
\end{aligned}
$$


Similarly for high origin agents the posteriors are

$$
\begin{aligned}
& \operatorname{Pr}\{A \mid 1,0 ; q\}=0, \\
& \operatorname{Pr}\{A \mid 1,1 ; q\}=\frac{p}{1-d(1-p)\left(1-q_{1, a}\right)} .
\end{aligned}
$$

Note that social movement makes a definitive signal regardless of parameters, whereas posteriors about agents who do not change class are affected by the model's parameters. The negative externality induced by approbation seeking shows in $\partial \operatorname{Pr}\{A \mid 0,0 ; q\} / \partial q_{0, A}$ and $\partial \operatorname{Pr}\{A \mid 1,1 ; q\} / \partial q_{1, a}$ both being negative.

Agents act as risk-neutral utility maximizers, simply comparing expected utilities. For high-ability lower class agents

$$
E U_{0, A}=\left\{\begin{array}{l}
u(1+\lambda \operatorname{Pr}\{A \mid 0,1 ; q\})+(1-u) \lambda \operatorname{Pr}\{A \mid 0,0 ; q\}-c, e_{i}=E, \\
\lambda \operatorname{Pr}\{A \mid 0,0 ; q\}, e_{i}=e .
\end{array}\right.
$$

The other three cases unfold similarly. Defining $\Delta_{i, j}$ to be the difference in expected utility between high and low effort for individuals of origin $i$ and ability $j$, we can write the incentives towards high effort as

$$
\begin{aligned}
& \Delta_{0, A}=u+\lambda \frac{u(1-p)}{1-p q_{0} u}-c, \\
& \Delta_{1, a}=d+\lambda \frac{d p}{1-d\left(1-q_{1, a}\right)(1-p)}-c, \\
& \Delta_{0, a}=-c<0 \\
& \Delta_{1, A}=-c<0 .
\end{aligned}
$$

Low-origin low-ability and high-origin high-ability agents never have incentives to provide high effort, whatever the belief system $q$. On the other hand both high-origin low-ability and low-origin high-ability agents prefer high effort over some parameter range(s). In a world in which utility is driven purely by income $(\lambda=0)$, the previous expressions simplify to $\Delta_{0, A}=u-c$ and $\Delta_{1, a}=d-c$. As we are interested in the case in which social approbation creates motivation for people who otherwise would not expend high effort, it is assumed in what follows that $c \geq \max \{u, d\}$. In other words, we assume that income effects alone are not enough to induce high effort.

To close the model we impose rational expectations, and look for equilibria in $q$. This gives four critical values: $\lambda_{0}, \Lambda_{0}, \lambda_{1}, \Lambda_{1}$. If $\lambda>\Lambda_{0}$ lower class agents give high effort; if $\lambda<\lambda_{0}$ lower class agents give low effort; for $\lambda>\Lambda_{1}$, high class agents give high effort; and for $\lambda<\lambda_{1}$, high class agents give low effort. From (2), consistency implies that $q_{0, a}=q_{1, A}=0$, i.e. the only equilibrium for low-origin, low-ability agents and high-origin, high-ability agents is to give low effort. Substituting the appropriate $q_{0, A}=1$ and $q_{0, A}=0$ into $\Delta_{0, A}$ yields

$$
\begin{aligned}
\Lambda_{0} & =\frac{c-u}{u(1-p)}(1-p u) \\
\lambda_{0} & =\frac{c-u}{u(1-p)}
\end{aligned}
$$

For low origin agents, when $\Lambda_{0} \leq \lambda \leq \lambda_{0}$, multiple equilibria exist: both low and high effort can be optimal for high ability low class individuals as a group. The multiplicity 
effect that arises here for intermediate values of $\lambda$ is the same as in Piketty (1998). Two opposite opinions are possible in this parameter region: the view that lack of promotion expresses lack of talent, versus the view that lack of promotion merely reflects bad luck. Making the equivalent substitutions for high origin agents gives

$$
\begin{aligned}
\lambda_{1} & =\frac{c-d}{p d}(1-d(1-p)) \\
\Lambda_{1} & =\frac{c-d}{p d}
\end{aligned}
$$

For $\lambda_{1}<\lambda<\Lambda_{1}$ upper class agents do not act monolithically, rather only a proportion $q_{1, a}^{*} \in(0,1)$ provide high effort. Solving $\Delta_{1, a}\left(q_{1, a}\right)=0$ yields

$$
q_{1, a}^{*} \equiv q^{*}=1+\frac{\lambda p}{(c-d)(1-p)}-\frac{1}{d(1-p)},
$$

which satisfies $q^{*}\left(\lambda_{1}\right)=0$ and $q^{*}\left(\Lambda_{1}\right)=1$. Optimal effort levels in relation to the strength of the approbation motive $\lambda$ are summarized in Proposition 1.

Proposition 1 Equilibrium effort levels.

- For low-origin agents:

$$
q_{0, A}^{*}= \begin{cases}0 & \lambda<\Lambda_{0} \\ \{0,1\} & \Lambda_{0} \leq \lambda \leq \lambda_{0} \\ 1 & \lambda>\lambda_{0}\end{cases}
$$

- For high origin agents:

$$
q_{1, a}^{*}= \begin{cases}0 & \lambda<\lambda_{1}, \\ q^{*} & \lambda_{1} \leq \lambda \leq \Lambda_{1}, \\ 1 & \lambda>\Lambda_{1} .\end{cases}
$$

Proof. Straightforward from the definitions and the expressions in Equation (2).

When approbation is little valued, effort levels are low, and the opposite happens when approbation is highly valued. In intermediate regions, for high-origin agents, a non-extreme proportion of low-ability agents provide high effort; whereas for low-origin agents there are multiple equilibria: either all high-ability agents provide high effort, or they all provide low effort.

The effects of the parameters of the model are easily seen. Dropping ability subscripts, we focus on the potentially mobile sub-classes: high-ability poor and low-ability rich. Not surprisingly, the incentives towards high effort are increasing with the approbation motive in both social classes: $\partial \Delta_{0} / \partial \lambda, \partial \Delta_{1} / \partial \lambda>0$. Regarding the public belief about high effort we have $\partial \Delta_{0} / \partial q_{0}>0$ and $\partial \Delta_{1} / \partial q_{1}<0$, which explains multiple equilibria in the lower class and the interior equilibrium in the upper. The derivatives of the roots with respect to the stochastic components of social mobility $u$ and $d$ are all negative, as increasing mobility 
( $u$ or $d$ ) gives high effort a higher expected return. Finally regarding $p$, the prevalence of high ability, the effects are $\partial \Delta_{0} / \partial p<0$ and $\partial \Delta_{1} / \partial p>0$. If I am lower class and high-ability, and almost everyone is low-ability (as would be implied by a low $p$ ), I gain a lot of prestige by signalling my high ability. When everyone is high-ability, on the other hand, the fact that I signal my ability will not make a large difference in terms of prestige since I am already "presumed" to be high-ability. High effort is thus less attractive. For low-ability high society agents things are reversed: if almost everyone in the population is high-ability and I fail to remain high society, I lose a lot of prestige because society easily identifies me as low-ability. When everyone is low ability on the other hand high effort is less attractive. Thus to induce high effort, a stronger approbation motive is needed for the poor if high-ability is common, whereas the opposite holds for the rich: $\partial \lambda_{0} / \partial p, \partial \Lambda_{0} / \partial p>0$ and $\partial \lambda_{1} / \partial p, \partial \Lambda_{1} / \partial p<0$.

It follows from Proposition 1 that if $\Lambda_{0} \leq \lambda \leq \lambda_{1}$ we can have a situation in which the poor strive to rise, and the rich let chance determine their fates. Such a situation has visible meritocratic elements as the combination of talent and effort exists and is rewarded; however it only applies to the low class. Society views success as signalling ability rather than mere chance, and self made men enjoy approbation. On the other hand, if $\Lambda_{1} \leq \lambda \leq \lambda_{0}$ the poor give up their aspirations and the rich work to maintain their position. In this situation society is strongly dynastic, with family lines occupying the same social class for ever and no lower class individual ever rising. There society validates the view that social ascension is despicable. In the next section we study the long run implications of individuals' optimal decisions.

\subsection{The evolution of social structure}

Observation of modern societies shows not only that individuals move from one class to another, but also that the overall structure of classes continually changes over time. ${ }^{10} \mathrm{We}$ study that issue in the overlapping structure that has been set forth, with social class being inherited without error. Social structure will evolve as a discrete time process with effort levels determining social movements, and the resulting structure being considered in the next generation's decisions regarding effort provision. Let $x(t)$ be the measure of the upper class at time $t$ and define $\bar{x}$ as the stationary (long run) measure of high society. We can then state the following.

Proposition 2 Consider three cases, determined by the equilibrium behaviour of the upper class.

- Suppose $\lambda<\lambda_{1}$, i.e. low effort is optimal for low-ability high-origin agents.

$$
\bar{x}=\left\{\begin{array}{cl}
0 & \lambda<\Lambda_{0}, \\
\left\{0, x^{*}=\frac{u p}{u p+d(1-p)}\right\} & \Lambda_{0} \leq \lambda \leq \lambda_{0} \\
x^{*}=\frac{u p}{u p+d(1-p)} & \lambda \geq \lambda_{0} .
\end{array}\right.
$$

\footnotetext{
${ }^{10}$ See Erikson and Goldthorpe (1992) for example.
} 
- Suppose $\Lambda_{1}<\lambda$, i.e. high effort is optimal for low-ability high-origin agents.

$$
\bar{x}=\left\{\begin{array}{cl}
x(0) & \lambda<\Lambda_{0} \\
\{1, x(0)\} & \Lambda_{0} \leq \lambda \leq \lambda_{0} \\
1 & \lambda \geq \lambda_{0}
\end{array}\right.
$$

- Suppose $\lambda_{1} \leq \lambda \leq \Lambda_{1}$, i.e. a share $q^{*}$ of low-ability high-origin agents provides high effort.

$$
\bar{x}=\left\{\begin{array}{cl}
0 & \lambda<\Lambda_{0}, \\
\left\{0, x^{* *}=\frac{u p}{u p+d(1-p)\left(1-q^{*}\right)}\right\} & \Lambda_{0} \leq \lambda \leq \lambda_{0} \\
x^{* *}=\frac{u p}{u p+d(1-p)\left(1-q^{*}\right)} & \lambda \geq \lambda_{0} .
\end{array}\right.
$$

Proof. If the low-ability high origin agents give low effort, they exit from the upper class, causing the upper class to decline at a rate $-(1-p) d$. If the high-ability low origin agents give high effort, they enter the upper class at a rate $(1 / x-1) p u$. If only the first motion exists (when $\lambda<\lambda_{1}$ and $\lambda<\Lambda_{0}$ ) then the only steady state of the system is $\bar{x}=0$. When only the second motion exists, each period the upper class grows, and in the limit $\bar{x}=1$ is the only steady state of the system. When both motions exists, then the rate of change is $(1 / x-1) p u-(1-p) d$ which has a fixed point at $x=x^{*}=u p /(u p+(1-p) d)$. As the slope of the map at that point is less than one $x^{*}$ is stable. In the intermediate range $\Lambda_{1} \leq \lambda \leq \lambda_{1}$ the upper class only decreases at a rate $-(1-p)\left(1-q^{*}\right) d$, hence the result. The different cases follow quite simply from these components.

Results both on effort levels and social structure are encapsulated by critical values $\lambda_{0}, \Lambda_{0}, \lambda_{1}$ and $\Lambda_{1}$ which, under different parameter values, occupy different positions along the approbation motive axis. There are, however, essentially two general cases: when the lower class thresholds are below the upper class ones, and vice versa. Which situation obtains depends on the prevalence of high ability. As $\partial \lambda_{0} / \partial p, \partial \Lambda_{0} / \partial p>0$ and $\partial \lambda_{1} / \partial p, \partial \Lambda_{1} / \partial p<0$ the first situation $\Lambda_{0}<\lambda_{0}<\lambda_{1}<\Lambda_{1}$ obtains when talent is rare ( $p$ low) whereas the second situation $\lambda_{1}<\Lambda_{1}<\Lambda_{0}<\lambda_{0}$ is associated with talent being common ( $p$ high). The results from Propositions 1 and 2 are summarized in Figure 1 for the two polar orderings mentioned above. ${ }^{11}$

Consider first the extreme cases of very weak or very strong approbation motives. When approbation motives are weak all agents give low effort and the less able members of the upper class (of which each generation has a share $1-p$ ) continually move down to join the lower class. We have a social system that behaves like a decaying dynasty. Eventually, by this attrition, the upper class is reduced to zero and while agents continue to value approbation, the concern for status is no longer manifest since there is no social mobility. By contrast, when status matters a lot, everyone gives high effort, and the upper class has a dynastic component (no one leaves it) but is continuously entered by lower class high-ability strivers (of which each generation has a share $p$ ), yielding a diluted dynasty. Here there

\footnotetext{
${ }^{11}$ The three other possible orderings of the roots along the approbation axis yield situations which are similar to but slightly more intricate than the two we present.
} 


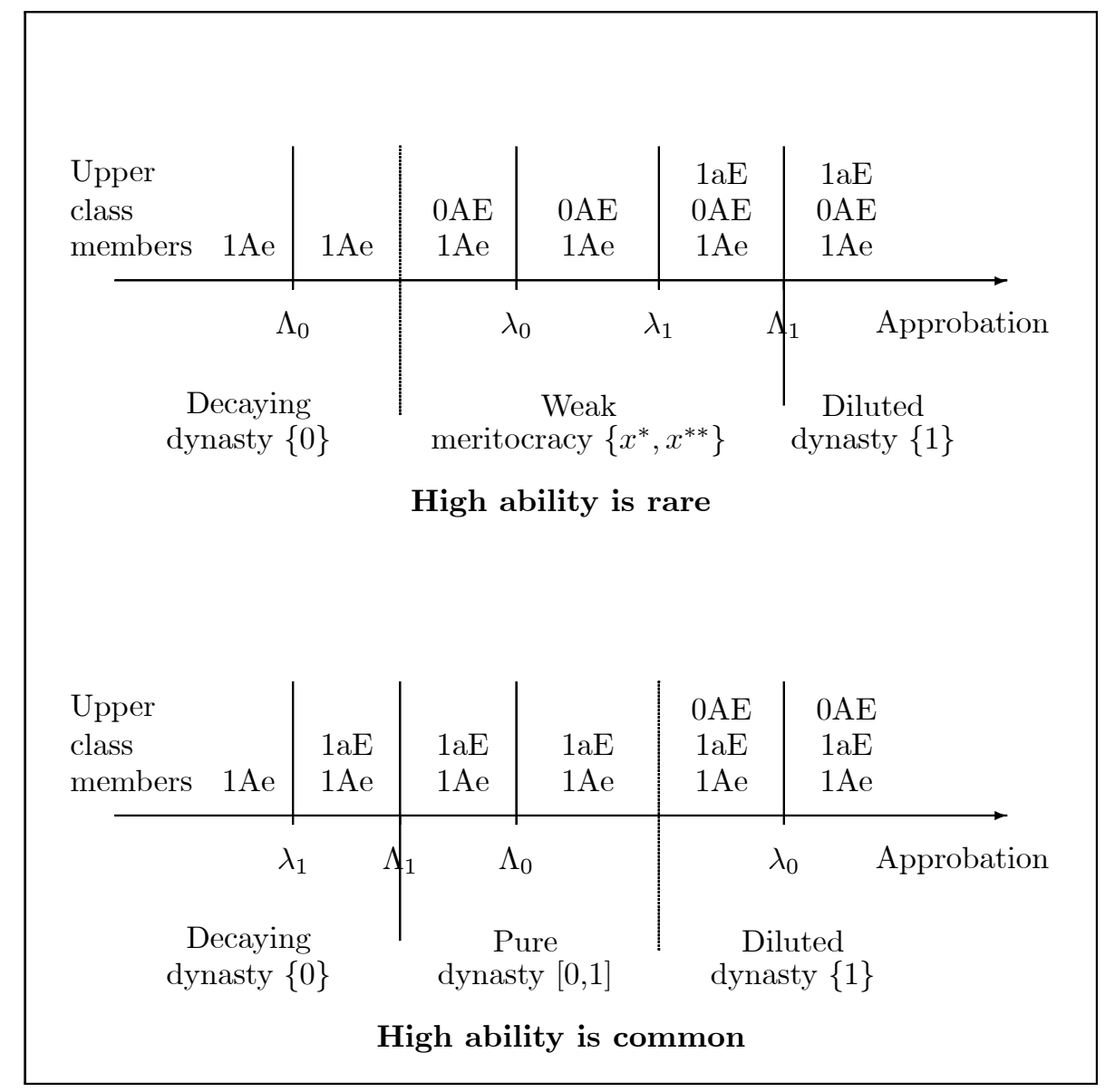

Figure 1: Social organization as the approbation motive is varied.

is a combination of dynastic and meritocratic elements in the social structure. Eventually, though, everyone becomes a member of the upper class and again approbation-seeking ceases to be relevant. The intermediate cases display a richer behaviour.

For intermediate $\lambda$-values, we can first observe situations in which both up and down social mobility take place (low $p$, upper part in Figure 1). Turmoil in the social structure has meritocratic elements, as high-ability lower class workers rise, and low-ability upper class shirkers fall $\left(\lambda_{1}>\lambda>\Lambda_{0}\right)$. (It is only weakly a meritocracy as high-ability shirkers do not fall out of the upper class.) For this to happen it must be the case that high ability is relatively rare. Thus only when approbation is granted for rare traits will a meritocratic society be observed. On the other hand, again in the middle ground, we can get situations with a completely frozen social structure in which pure dynasties exist $\left(\Lambda_{1}<\lambda<\Lambda_{0}\right)$. This occurs when high ability is common (high $p$, lower part in Figure $1)$. Thus when approbation is granted for common traits, even though promotion and demotion mechanisms are inherently meritocratic, society does not look like a meritocracy but rather like an archetypal dynasty. 


\subsection{Discussion}

Do the informational constraints bearing on the agents significantly affect the behaviour of the system? Some types of abilities may be difficult even for the agent to observe, and some types of effort may be more obvious than others. Thus in principle there are four possible information settings: the observability of effort crossed with the observability of ability. Simply by re-doing the above calculations under different information regimes, it can be observed that as knowledge asymmetries decrease, the strength of the approbation motive needed to induce high effort increases. It becomes more difficult to induce a change of public perception of ability through social mobility. In the extreme case where public and private knowledge is identical, involving knowledge of effort and ignorance of ability, no finite utility from approbation is high enough to induce any agent to high effort. Which of the two intermediate knowledge regimes ${ }^{12}$ is more conducive to high effort depends on the other parameters (the levels of mobility $u$ and $d$ and the prevalence of high ability).

Regarding the effect of $u$ and $d$, symmetric upward and downward mobility $(u=d)$ imply that pure dynasties exist only when high ability is common $(p>1 / 2)$ while weak meritocracy exists only when high ability is uncommon $(p<1 / 2)$. To look at asymmetric mobility, fix $u$ and denote $p^{*}=\arg \left\{\Lambda_{1}=\lambda_{0}\right\}$ the value of $p$ at which a dynastic regime can appear (recall meritocracy demands $\lambda>\Lambda_{0}$ and $\lambda<\Lambda_{1}$ ). Differentiation yields $\partial p^{*} / \partial d<0$, i.e. increasing the relative ease of downwards mobility increases the range of $p$-values compatible with pure dynasties. Now denote $p^{*}=\arg \left\{\Lambda_{0}=\lambda_{1}\right\}$ the value of $p$ at which a meritocracy can emerge. Again $\partial p^{*} / \partial d<0$, thus increasing the relative ease of downwards mobility diminishes the range of $p$-values compatible with weak meritocracy. As downward mobility becomes stronger, observing a dynastic structure becomes more likely. Turning to the stationary roots, as one would expect, the size of the upper class decreases with the relative ease of downward mobility $\left(\partial x^{*} / \partial d<0\right)$. The effect of $u$ is naturally the opposite. (In addition, almost everywhere $\partial x^{*} / \partial p>0$, i.e. the size of the upper class increases with the prevalence of high ability) Also note that having $u>d$ implies that $x^{*}>p$, while if $d>u$ then $x^{*}<p$. Put in words, if upward mobility is (relatively) easy, then the high class will accommodate all of the high-ability agents, and some of the low-ability well-born. If upward mobility is (relatively) difficult, then high-ability low-origin agents cannot rise, and the upper class does not contain all of the high-ability agents in the population.

We have assumed above that ability was distributed independently across agents. This is a relatively strong assumption, however, as one might think that ability is correlated either with origin class, or with parental ability.

The first case, in which ability is (positively) correlated with birth class, can be readily accommodated in the model. Letting the probabilities of high ability differ for the two classes by introducing $p_{0}$ and $p_{1}$ in Equation 2 changes the critical values of $\lambda$ and thereby changes the relative sizes of the regions in Figure 1. In terms of the evolution of social structure, the rates at which classes change depend on both $p_{0}$ and $p_{1}$. When there is only attrition or growth the steady states at 0 and 1 are preserved. When both classes display in and out flows the fixed points $x^{*}$ and $x^{* *}$ now have values which depend on $p_{0}$ and $p_{1}$.

\footnotetext{
${ }^{12}$ The two intermediate regimes are public and private ignorance of ability with public ignorance but private knowledge of effort; and public and private knowledge about effort with public ignorance and private knowledge about ability.
} 
Modulo that difference the system displays the same qualitative behaviour.

The case in which individual ability is correlated with parental ability is slightly more complicated. Studying it precisely demands keeping track of the measure of high ability individuals in each class as they change in time. The proportion of high ability agents in each class is no longer constant $(p)$, but changes from period to period. This implies that the critical $\lambda$ values will change over time. For large or small values of $\lambda$ this does not cause particular problems, as either all potentially mobile agents work (and rise) or none do (and fall). While this changes the proportion of high ability agents in the origin classes, the implied movements in critical $\lambda$ values does not change optimal behaviour. Difficulties in analysing the dynamics arise, however, when $\lambda$ is near the initial critical values. Changing proportions of high ability agents in the two classes can change critical values such that the optimal behaviour for particular types of agents changes from one period to the next. ${ }^{13}$

\section{Social competition}

In the exposition so far we have assumed that the size of the upper class has no effect on the income of its members $(r(0)=0$ and $r(1)=1)$. But competition for places in the upper class is a common feature of modern societies. ${ }^{14}$ The simplest way to incorporate a form of competition in our model is to assume that the income of upper class members is a function of the class size. ${ }^{15}$ We assume that each new entrant to high society inflicts a negative income externality on the other members, so the attractiveness of the upper class club falls as it grows in size. ${ }^{16}$ In this setting the income in the upper class is a decreasing function $\xi$ of the measure $x$ of individuals who belong to it. Thus in addition to the negative externality induced by approbation-seeking, there is also a "real" income effect.

Incentives for high effort in this case are identical to those in the previous setting with the exception that income in the upper class is $\xi(x)$ rather than 1. Following Equations 2,

\footnotetext{
${ }^{13}$ Take the case of perfect correlation, assuming low ability is rare and the approbation motive is low, i.e. $\lambda \leq \Lambda_{0}<\lambda_{0}<\lambda_{1}<\Lambda_{1}$. All individuals expend low effort. Supposing that initially the measure of high ability is $p$ in both classes, after the first period only high ability remain in the upper class and the share of high ability in the lower class becomes $p x /(x+(1-p)(1-x))<p$. As $\partial \lambda_{0} / \partial p, \partial \Lambda_{0} / \partial p>0$ the critical $\lambda$ for the lower class are shifted left. Thus now high effort can become an equilibrium for the high ability poor.

${ }^{14}$ See for example Hirsch (1976) or Frank(1985b).

${ }^{15}$ We should acknowledge here that this does not constitute competition for approbation. The value of approbation is not affected by the number of people receiving it. But as utility is additive in income and approbation, this remains a simple way to introduce the feedback from social structure to effort levels.

${ }^{16}$ There are several possible reasons for a decrease in income with class size. If the class is correlated with professions, a simple market effect implies that an increase in the number of professionals (doctors, lawyers and so on) will drive the wage premium down. In some places this is institutionalized: in French medical school for example, there is a numerus clausus applied at the end of the first year of study. Effort applied to enter the first year class can be wasted, and so the expected value of it falls as the number doing so increases. An alternative interpretation could be to consider there is a taste for distinction, which lowers the attractiveness of high society: competition between the wannabes and the incumbents results in lower payoffs for everyone.
} 
we can write these incentives for our four types of agents directly as:

$$
\begin{aligned}
& \Delta_{0, A}=u \xi(x)+\lambda u \frac{1-p}{1-p q_{0, A} u}-c, \\
& \Delta_{1, a}=d \xi(x)+\lambda \frac{d p}{1-d\left(1-q_{1, a}\right)(1-p)}-c, \\
& \Delta_{0, a}=-c<0 \\
& \Delta_{1, A}=-c<0 .
\end{aligned}
$$

As in the previous section, the only equilibrium for low-origin, low-ability agents and highorigin, high-ability agents is to give low effort. For the other two types, we again look for rational expectations equilibria. In a world without approbation we get $\Delta_{0, A}=u \xi(x)-c$ and $\Delta_{1, a}=d \xi(x)-c$, so we assume that $c \geq \max \{u \xi(0), d \xi(0)\}$.

\subsection{Equilibrium effort levels}

Proceeding analogously to the previous section, we now define four critical values of the size of the upper class $\left(x_{0}, X_{0}, x_{1}, X_{1}\right)$ as follows:

$$
\begin{aligned}
& \text { if } x<X_{0} \text { then lower class agents give high effort, } \\
& \text { if } x>x_{0} \text { then lower class agents give low effort, } \\
& \text { if } x<X_{1} \text { then upper class agents give high effort, } \\
& \text { if } x>x_{1} \text { then upper class agents give low effort. }
\end{aligned}
$$

In contrast to the exposition in Section 3.1, the results are not stated in terms of the approbation motive, but rather in terms of the measure of the upper class. The focus here is on the interaction between social structure and individual incentives, i.e. how social mobility affects and is affected by the composition of society. Using these definitions and Equations 7 we can write the critical values as follows.

Proposition 3 The critical sizes of the upper class with social competition are

$$
\begin{array}{r}
x_{0}=\xi^{-1}\left(\frac{c}{u}-\lambda(1-p)\right), \\
X_{0}=\xi^{-1}\left(\frac{c}{u}-\lambda \frac{1-p}{1-p u}\right), \\
X_{1}=\xi^{-1}\left(\frac{c}{d}-\lambda p\right), \\
x_{1}=\xi^{-1}\left(\frac{c}{d}-\lambda \frac{p}{1-(1-p) d}\right) .
\end{array}
$$

Proof. Assuming parameter values such that the four roots belong to $[0,1]$, these follow directly from substituting $q_{0, A}$ and $a_{1, a}$ into $\Delta_{0, A}$ and $\Delta_{1, a}$. When only some of the roots belong to $[0,1]$, the discussion reduces to sub-cases of those discussed in the following paragraph.

Note that as both expressions in Equation (7) are strictly decreasing with $x$, all critical values, provided they belong to $[0,1]$, are unique. For the roots to belong to $[0,1]$ it must be the case that $\Delta_{0}(0,1), \Delta_{1}(0,0)>0$ and $\Delta_{0}(1,0), \Delta_{1}(1,1)<0$. For low origin agents, 
when $x_{0} \leq x \leq X_{0}$, multiple equilibria exist: both low and high effort can be optimal for high ability low class individuals as a group. When $X_{1} \leq x \leq x_{1}$, a non-extreme proportion of upper class low-ability agents produces high effort. Solving $\Delta_{1, a}=0$ gives that proportion as

$$
q^{*}(x)=1-\frac{1}{d(1-p)}+\frac{\lambda p}{(1-p)(c-d \xi(x))} .
$$

In the presence of social competition the optimal effort levels are dependent on the measure of the upper class. In this case the dynamics of the class structure become interesting as incentives to high effort can change over time as the upper class grows or shrinks. The presence of critical values of $x$ at which incentives, and thus behaviour, change implies that the iterated map describing the evolution of $x$ is piecewise defined, as is illustrated below.

\subsection{The evolution of social structure}

As in Section 3.2, we have a structure in which agents' origin class is inherited without error from their parents. In addition we have introduced an interdependence in income across individuals. One possible way of determining equilibrium behaviour could be to again impose rational expectations as the equilibrium concept. However solving directly for the rational expectations equilibrium prevents us from examining dynamics. Thus, since we are interested in society's evolution and in the (presumably) richer dynamics that the existence of a feedback from social structure to effort levels generates, we make the simple assumption that individuals' beliefs about class size are myopic. Changes in structure are determined by equilibrium effort levels, which are in turn based upon the class structure left by previous generations. This is a reasonable assumption if $u$ and $d$ are small, for in this case social structure evolve slowly as only a small proportion of those fit to change classes will in fact do so. Thus under this expectation structure, individuals base their effort decisions on the assumption that the class structure will remain unchanged through their lifetimes. This permits us to ask whether cycles in the social structure could emerge.

The presence of multiple equilibria complicates the exposition quite significantly, so we make the simplifying assumption that in the region $\left[x_{0}, X_{0}\right]$ of multiple equilibria for the high ability lower class, high effort is selected. With this tie-breaking rule, only three regimes are possible. These are driven by $p$, since the critical values of $x$ respond to changes in $p: \partial X_{0} / \partial p<0$ while $\partial x_{1} / \partial p, \partial X_{1} / \partial p>0$.

The dynamics of the system can be captured in a straightforward way be defining separately the rates of up and down mobility. Define $\tilde{q}_{1}(x)$ as

$$
\tilde{q}_{1}(x)= \begin{cases}0 & x>x_{1}, \\ q^{*}(x) & X_{1} \leq x \leq x_{1}, \\ 1 & x<X_{1},\end{cases}
$$

and similarly

$$
\tilde{q}_{0}(x)= \begin{cases}0 & x>X_{0} \\ 1 & x \leq X_{0}\end{cases}
$$

Now for any $x$, the rate of change from down mobility is equal to $D=(1-p) d\left(1-\tilde{q}_{1}(x)\right)$, whereas up mobility is defined as $U=(1 / x-x) p u \tilde{q}_{0}(x)$. The rate of change in $x$ is then 
simply $U-D$. From this and the definition of $q^{*}(x)$ in Equation 8, three propositions follow straightforwardly.

Proposition 4 With a high public belief in individual ability, equilibrium is characterized by labouring rich, work-shy poor and a dynastic class structure with the upper class of any measure between $X_{0}$ and $X_{1}$.

Proposition 5 With an intermediate public belief in the likelihood of high individual ability, there are two possibilities. Equilibrium is characterized by either labouring poor, lazy rich and a non-dynastic upper class of measure $x^{* *}=\arg _{x}\left\{u p(1 / x-1)=\left(1-q^{*}(x)\right)(1-\right.$ $p) d\}$ if $x^{* *}<X_{0}$. When $x^{* *}>X_{0}$ equilibrium is characterized by the absence of stationary class structures and individual effort levels, with the measure of the upper class cycling around $X_{0}$.

Proposition 6 With a low public belief in the likelihood of high individual ability, there are three possibilities. Equilibrium is characterized by labouring poor, lazy rich and a nondynastic upper class of measure $x^{* *}$ if $X_{1}<x^{* *}<x_{1}$. The same form of social organization prevails with an upper class of measure $x^{*}=u p /(u p+(1-p) d)$ if $x_{1}<x^{*}<X_{0}$. Finally cycles obtain around $X_{0}$ if none of the previous equilibria exists in the relevant intervals.

In the following paragraphs we discuss these propositions more in detail and illustrate them with a simple example. In this example we set the basic parameters of the model as follows: costs of effort, $c=0.2$, probability of up and down mobility, $u=d=0.1$, the utility value of approbation $\lambda=2.5$, and finally the function mapping the size of the upper class into its income, $\xi(x)=(1-x)^{2}$. The three sections that follow illustrate the propositions by introducing different values of $p$, and generating the iterated map of $x$.

\subsubsection{Common high ability}

Assume first that high ability is so common that the roots are ordered as $X_{0}<X_{1}<$ $x_{1}$. Specifically, in the example described above, set $p=0.6$. The map representing the evolution of high society is given in Figure 2.

There is a discontinuity at $X_{0}$, then a continuum of stationary points between $X_{0}$ and $X_{1}$. Two other distinct segments exists: between $X_{1}$ and $x_{1}$ and finally above $x_{1}$. The process will rest at some point between $X_{0}$ and $X_{1}$, depending on initial conditions. Note that the measure of possible equilibria is increasing with society's belief in the likelihood of high ability: $X_{0}$ decreases with $p$ while $X_{1}$ increases with $p$.

If high ability is widespread, a striving upper class (whose members thus never experience downwards social mobility) and a work-shy lower class (whose members thus never move upwards) coexist, and the stable measure of the upper class can take any value between $X_{0}$ and $X_{1}$. Society is segmented into two groups between which no one travels. Social structure, and therefore the income distribution, is frozen.

\subsubsection{Intermediate prevalence of high ability}

Assume now that high ability is moderately prevalent, so that the roots are ordered as $X_{1}<X_{0}<x_{1}$. In this case there are social structures (values of $x$ ) such that high society remains attractive to poor people while it has stopped being so for rich people. 


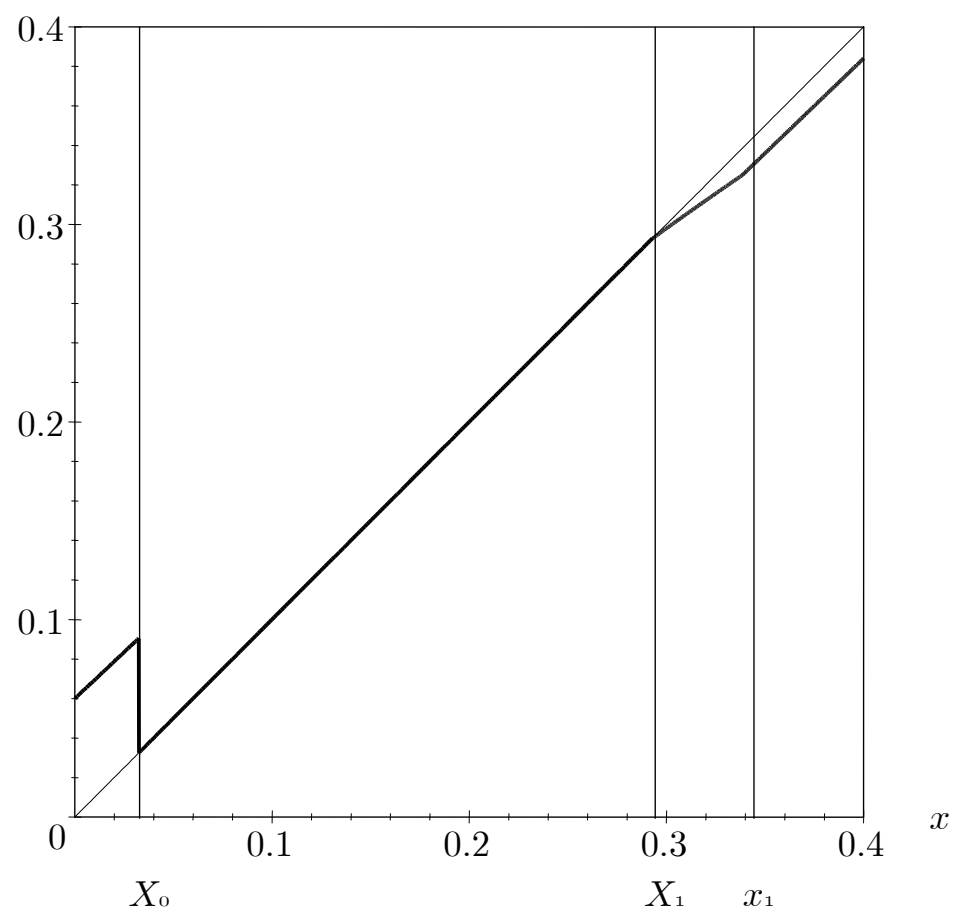

Figure 2: The map describing the evolution of the upper class in the example with high prevalence of high ability $(p=0.6)$ and the roots ordered as $X_{0}<X_{1}<x_{1}$.

With intermediate amounts of high ability the set of stationary states shrinks to a point, which is characterized by systematic changes in class composition: low origin individuals continually move into the upper class through high effort, and upper class members rely on luck to stay there, and so continually fall. Depending on the parameter values it is also possible that no stationary point exists, in which case cycles obtain. To illustrate, set $p=0.507$ in the example. In this case the map representing the evolution of high society is given in Figure 3.

There is a first change in the slope at $X_{1}$, before a discontinuity at $X_{0}$. A third piece exists between $X_{0}$ and $x_{1}$ and finally the last part of the map to the right of $x_{1}$. From the proposition we know that two cases are possible. Either the crossing takes place between $X_{1}$ and $X_{0}$ and then a unique stationary point obtains, or the crossing is not in that segment and we have no stationary point. The illustration is of the latter type. Left of $X_{0}$ the upper class tends to grow while right of $X_{0}$ it tends to shrink. As a result the measure of high society cycles around $X_{0}$ and never settles down. ${ }^{17}$

\subsubsection{Rare High Ability}

Suppose now that $p$ is low enough so that the roots are ordered as $X_{1}<x_{1}<X_{0}$. The resulting situation is similar to the previous one as it also presents the possibility that no

\footnotetext{
${ }^{17}$ For these parameter values the system settles into a six-period cycle, with $x=$ ( 0.2004, 0.1905, 0.1811, 0.1727, 0.1664, 0.1616,..).
} 


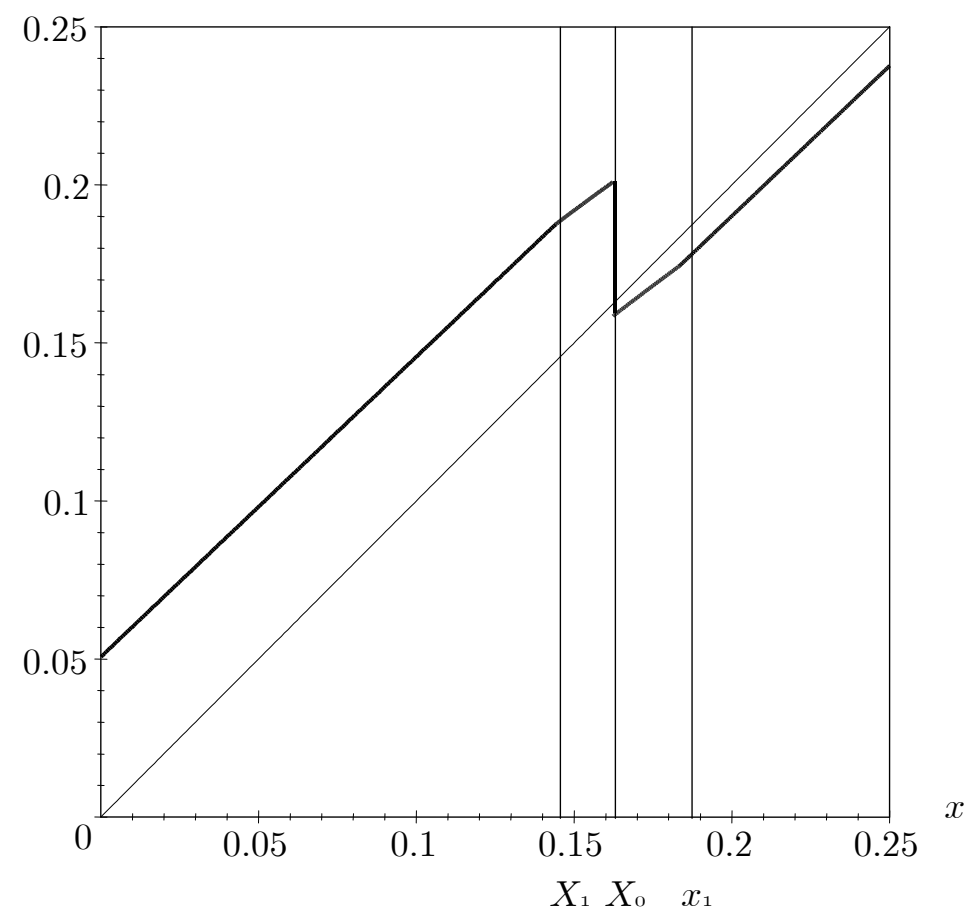

Figure 3: The map describing the evolution of the upper class in the example with intermediate prevalence of high ability $(p=0.507)$ and the roots ordered as $X_{1}<X_{0}<x_{1}$.

stationary structure exists.

The stationary state is again characterized by systematic changes in class composition, with low origin individuals rising through expenditure of effort, and the upper class again relying on luck to stay there, and so typically falling. Cycles also exist in which society never settles down. In the example set $p=0.41$. The map representing the evolution of high society is given in Figure 4.

Figure 4 and Figure 3 yield the same conclusion. This time in Figure 4 though there are two changes in the slope of the map, at $X_{1}$ and $x_{1}$, before the discontinuity at $X_{0}$ and then a final new piece of the map. The example here has no stationary measure of high society as left of $X_{0}$ the upper class tends to grow while right of $X_{0}$ it tends to shrink. As a result cycles obtain. ${ }^{18}$

\subsection{Welfare}

Consider total utility as the measure of social welfare. Given that low-ability poor and high-ability rich are immobile, it is not surprising that their maximum contribution to social welfare obtains when they expend low effort. This is both privately and socially optimal. The maximal total contribution of the high-ability rich and the low-ability poor is $x p(\xi(x)+\lambda)+(1-x)(1-p) \lambda p$. The cases of the high-ability poor and low-ability

\footnotetext{
${ }^{18}$ For these parameter values, the stationary cycle is $x=(0.3083,0.3184,0.3276, \ldots)$.
} 


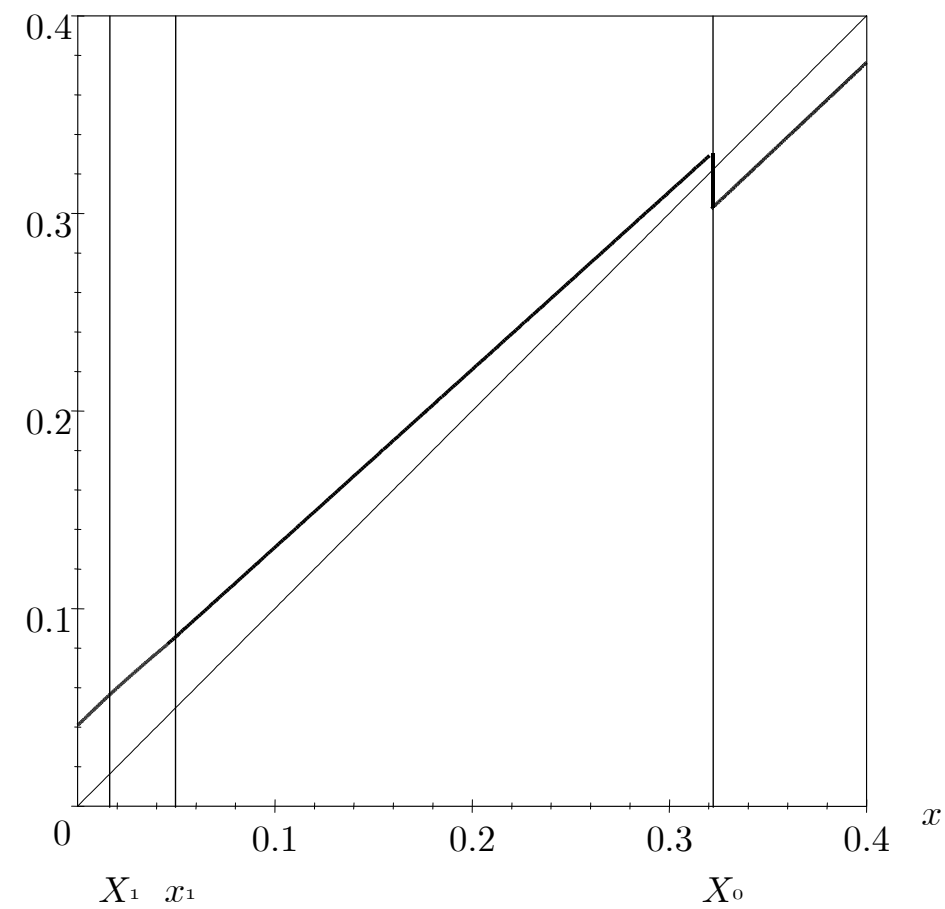

Figure 4: The map describing the evolution of the upper class in the example with low prevalence of high ability $(p=0.41)$ and the roots ordered as $X_{1}<x_{1}<X_{0}$.

rich need more care. When the high-ability poor expend high effort, their contribution to social welfare is $(1-x) p[u(\xi(x)+\lambda)+(1-u) \lambda p(1-u) /(1-p u)-c]$. Similarly, if they expend low effort: $(1-x) p \lambda p$. Thus socially optimal switching from low to high effort should take place if

$$
\lambda>\lambda_{0}^{*}=\frac{c-u \xi(x)}{u(1-p)^{2}}(1-p u)
$$

Similarly the low-ability high origin agents' contribution to welfare when they produce high effort is $x(1-p)(\xi(x)+\lambda p-c)$ while for low effort it is $x(1-p)(1-d)(\xi(x)+\lambda p /[1-d(1-p)])$. Thus socially optimal switching from low to high effort should take place if

$$
\lambda>\lambda_{1}^{*}=\frac{c-\xi(x) d}{d p^{2}}(1-d(1-p)) .
$$

It is easily seen that $\lambda_{0}^{*}>\lambda_{0}$ and $\lambda_{1}^{*}>\Lambda_{1}$, i.e. there is a non-zero measure of $\lambda$ values in which agents produce high effort while social optimality demands low effort. This is true both of the lower class (this stems from the tie-breaking assumption of high effort in the region $\left[x_{0}, X_{0}\right]$ of multiple equilibria) and for the upper class (a measure $q^{*}(x)$ of them provides $E$ ). As a result, in this region of $\lambda$ values, for any class structure $x$ (including the stationary ones) more effort than socially optimal is provided, thus approbation-seeking results in a waste, the magnitude of which decreases with $u$ and $d$. The extent of this 
over-provision, as measured by the ratios $\lambda_{0}^{*} / \lambda_{0}$ and $\lambda_{1}^{*} / \Lambda_{1}$ changes with the prevalence of high ability: as high ability becomes more common, the region (of $\lambda$ ) of over-provision by the upper class falls, whereas the region of over-provision by the lower class increases.$^{19}$ The difference between social and private optimality arises because of two externalities that effort imposes on others. First, due to the application of Bayes' Rule, there is a competition for approbation, implying that if an agent switches from low to high effort he reduces the probability that other agents are considered high ability. Consequently others receive less approbation. Second, since high effort is a route into the upper class, expenditures of effort increase the size of the upper class, and thus reduce the income of everyone in it. As these are external effects, effort will, in general be over-supplied.

\section{Conclusion}

Although the prestige from being considered a talented person does not really affect one's economic well-being, it is something we tend to value positively. What I wear, which car I drive and where I spend my week-ends can all be considered correlated with ability, but probably a more revealing signal is my social mobility, as measured by my educational or professional achievement relative to that of my parents. The model developed here is about how individual utility maximization affects social structure and social dynamics, and about how the system of social mobility self-regulates.

In the model, an inherent concern for social approbation (a concern for status, if status is determined by ranking on the scale of approbation) is transformed into an instrumental concern for social class. It is not simply class per se, however, in the sense in which approbation arises from class in an aristocracy. Rather, it is a concern for what we have termed "destination class". That is, the class an agent is in after mobility has taken place. Comparing origin and destination class is what permits public inference about the trait on which approbation is determined. Thus it is mobility between classes (or lack of it) rather than the class into which one is born that matters for our agents. Because mobility is a source of well-being to individuals and they actively seek it, social structure changes over time and we study the types of organizations that emerge.

One striking result that emerges is that in spite of the fact that social mobility is determined purely on meritocratic principles, a dynastic social structure can emerge. One of the over-arching concerns in empirical studies of social mobility is the extent to which a society is "meritocratic". ${ }^{20}$ This debate is conducted by examining different empirical measures of mobility between social classes. But our results suggest that the issue may be more subtle. Is a society meritocratic if it has the right kind of mobility? Or is it meritocratic if it has the right kind of incentives? If the latter, it may not be enough to look at mobility in order to conclude that a society is or is not a meritocracy. When the trait on which social approbation is granted is relatively common, then a society with meritocratic incentives will have as its characteristic social "mobility regime", a pure dynasty. All children end up in the social class into which they were born. The explanation is that because everyone is presumed to be of high ability, if a low origin agent rises in social class

\footnotetext{
${ }^{19}$ This is seen simply by differentiating the ratios with respect to $p$.

${ }^{20}$ See the debate between Saunders (1997) who finds the UK to be highly meritocratic, and Breen and Goldthorpe (1999) who do not.
} 
this has little effect on people's estimates of his ability, since he was presumed to be high ability initially. Thus the effort needed to rise in status produces little value in terms of approbation. On the other hand, if a high origin agent falls, this is an unambiguous signal that he is of low ability, which will reduce significantly his utility from approbation. Thus the effort needed to stay in the upper class is worth it. These effects combine to produce a frozen inter-generational social structure.

Second, in the model we introduce a feedback between the social structure on the one hand, and effort and social mobility on the other. This implies that effort levels and social structure are jointly endogenized. From this second feature of the model we get the result that a multiplicity of dynastic societies can be observed in the long run when the prevalence of talent is high. Otherwise identical societies can have different class structures. On the other hand, either cycles or a weakly meritocratic stable organization are possible when talent is not too frequent. The upper class can grow for several periods as lower class agents work hard to move up, but then there can be a significant fall in its size, when the upper class gets too big. At this point the income level in the upper class falls below a threshold, and the upper class agents no longer find it advantageous to expend the effort to stay there, and there is a big shift in social structure as the low-ability rich abandon their class through lack of effort.

The model permits an interesting suggestion about how mobility could change over time. One can imagine that from time to time new approbation traits emerge. Suddenly something new, ability in mathematics for example, becomes highly esteemed. One would expect that initially esteem is given to relatively rare traits. When this is the case, social mobility itself demonstrates meritocratic features. When low ability is presumed (that is when the approbation trait is rare), then a rise by a low origin agents is an unambiguous signal of high ability, while the fall of a high origin agent will not change very much the public opinion of his ability. Thus low origin agents have strong incentives to work hard, high origin agents have only very weak incentives. High ability, industrious poor advance; low ability, lazy rich fall, and the mobility "looks meritocratic". But when a possession of a trait provides utility, a rational response is to invest. We often see parents forcing children to invest (typically in education) so they will acquire these rare traits for which approbation is granted. Rarity falls, and mobility will be reduced, possibly disappearing altogether as the trait becomes too common and society moves into a frozen dynastic structure. This changes not only the nature of mobility, but also which part of the population works hard. Initially it is the striving, high ability poor, eventually it is the defensive, low ability rich. If upper class income were determined not only by the size of the class but also by the ability of those earning it, social welfare could increase if high-ability agents populated the upper class. Thus a shift from an uncommon to common approbation trait, and the consequent move from a meritocracy to a dynastic structure would have negative implications for social welfare.

\section{References}

[1] Boudon, R. (1974) Education, opportunity and social equality, New York: Wiley. 
[2] Breen, R., Goldthorpe, J. (1999) "Class inequality and meritocracy: a critique of Saunders and an alternative analysis", British Journal of Sociology, 50, 1-27.

[3] Breen, R., Goldthorpe, J. (2001). "Class, Mobility and Merit: The Experience of Two British Birth Cohorts." European Sociological Review, 17, 81-101.

[4] Cole, H., Mailath, G., Postlewaite, A. (1992) "Social norms, savings behaviour and growth". Journal of Political Economy, 100, 1092-1125.

[5] Corneo, G., Jeanne, O. (1998) "Social organization, status and savings behaviour", Journal of Public Economics, 70, 37-51.

[6] Corneo, G., Jeanne, O. (1999) "Social organization in an endogenous growth model", International Economic Review, 40, 711-725.

[7] Deardon, L. S. Machin and H. Reed (1997) "Intergenerational mobility in Britain", Economic Journal, 107, 47-66.

[8] Erikson, R., Goldthorpe, J. (1992) The Constant Flux, Oxford, Clarendon Press.

[9] Erikson, R., Goldthorpe, J. (2002) "Intergenerational inequality: A sociological perspective", Journal of Economic Perspectives, 16, 31-44.

[10] Fershtman, C., Murphy, K., Weiss, Y., (1996). "Social status, education, and growth". Journal of Political Economy 106, 108132.

[11] Frank, R. (1985a) Choosing the Right Pond : Human Behavior and the Quest for Status, Oxford University Press, Oxford.

[12] Frank, R. (1985b) "The demand for unobservable and other nonpositional goods", American Economic Review, 75, 101-116.

[13] Funk P. (1996) "Relative needs, and the long run economic problem", unpublished.manuscript, Paris: Delta.

[14] Hirsch, F. (1976) Social limits to growth, Harvard University Press, Cambridge, MA.

[15] Ireland, N. (1998) "Status-seeking, income taxation and efficiency", Journal of Public Economics, 70, 99-113.

[16] Marshall, A. (1890) Principles of Economics. Macmillan, London (Reprinted 1962).

[17] Piketty, T. (1998) "Self-fulfilling beliefs about social status", Journal of Public Economics, 70, 115-132.

[18] Saunders, P. (1997) "Social mobility in Britain: An empirical evaluation of two competing theories" Sociology, 31,261-288.

[19] Savage, M. and M. Egerton (1997) "Social mobility, individual ability and the inheritance of class inequality" Sociology, 31, 645-672.

[20] Smith, A. (1776) The Wealth of Nations. Reprinted, Modern Library, New York, 1937. 
[21] Treiman, D., Ganzeboom, B. (1990) "Cross national comparative status-attainment research". Social Stratification and Mobility, 9, 105-127.

[22] Veblen, T. (1899) The Theory of the Leisure Class: An Economic Study of Institutions. Reprinted, Modern Library, New York, 1937.

[23] Weiss, Y., Fershtman, C. (1998) "Social status and economic performance: a survey", European Economic Review, 42, 801-820.

[24] Young, M. (1958) The Rise of the Meritocracy, London, Thames and Hudson. 